\title{
RED FOX CATCHES GOSLING
}

ANDREA CLARKE, 2C Photography, Weburn, SK.

On Wednesday 28 May 2014, [I took] just a couple of snap shots this evening. I wondered why this fox didn't leave when I stepped out of the truck. Turns out, its meal was in the grass! Looks like it's baby goose for supper. I think the gosling was still alive. I expected it to be more floppy if it were dead. Also, the eye is still shiny. Normally, eyes dry within minutes of death. The fox took off into the trees right after this shot, so it was a very brief episode!

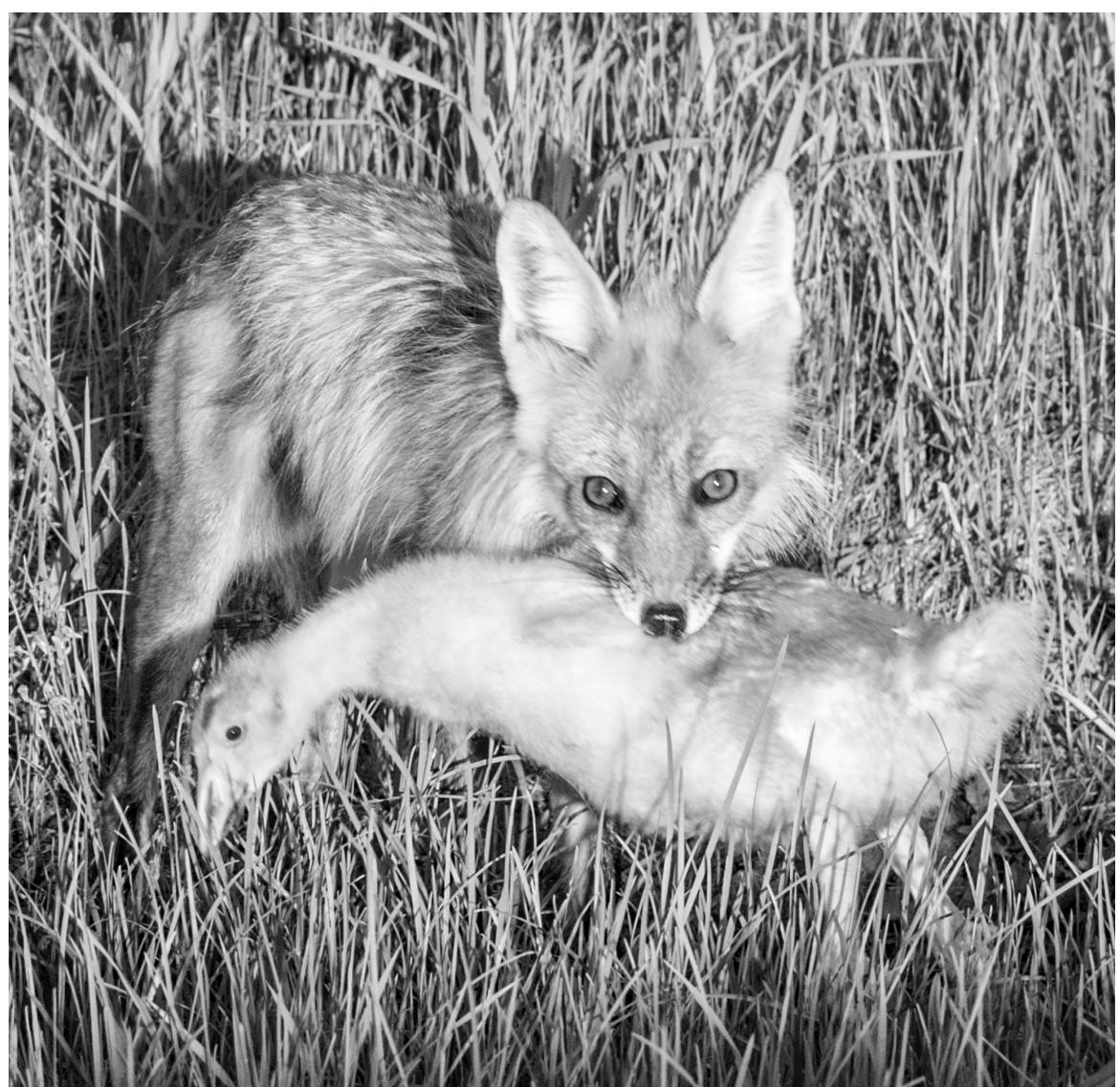

Red fox with Canada goose gosling - Andrea Clarke 2C Photography 